\title{
PLASMA ASSISTED CONVERSION OF CARBON DIOXIDE IN LOW-PRESSURE GAS DISCHARGES
}

\author{
S.V. Dudin, A.V. Zykov, S.D. Yakovin \\ V.N. Karazin Kharkiv National University, Kharkiv, Ukraine \\ E-mail:dudin@karazin.ua
}

Experimental results of comparative study of carbon dioxide conversion efficiency to $\mathrm{CO}$ and $\mathrm{O}_{2}$ in the plasmas of different low-pressure discharges are presented. Inductively coupled plasma source, magnetron discharge and anode layer discharge in Hall-type ion source were used in $\mathrm{CO}_{2}$ pressure range 0.5 ...3 mTorr. It is shown that the best combination of high conversion rate with significant energy efficiency of the conversion is demonstrated by the ICP source.

PACS: 52.77.-j

\section{INTRODUCTION}

The modern world has faced the problem of excessive emissions of greenhouse gases, particularly carbon dioxide, and, at the same time, with the growing need for carbon-containing resources. Thus, one of the greatest challenges of modern science and technology is the creation of "cyclic industry", in which exhaust gases containing $\mathrm{CO}_{2}$ are raw material for another production. In recent years increasing interest in the plasma conversion of greenhouse gases appears with the main focus on $\mathrm{CO}_{2}$ conversion into compounds such as methanol $\left(\mathrm{CH}_{3} \mathrm{OH}\right)$ or synthesis gas $\left(\mathrm{CO} / \mathrm{H}_{2}\right)$. There is the possibility of using $\mathrm{CO}_{2}$ as a fuel for space engines due to its presence in different space environments (atmosphere of Mars contains $95 \%$ of $\mathrm{CO}_{2}$ ).

Plasma conversion of carbon dioxide possesses some important advantages in comparison to classical thermal $\mathrm{CO}_{2}$ splitting and is actively researched $[1-10]$ with use of different kinds of gas-discharge plasma: glow discharge [1], dielectric barrier discharge (DBD) $[2,9,10]$, helicone discharge [4], microwave discharge [8]. There are theoretical studies $[4,5]$ where $\mathrm{CO}_{2}$ plasma is analyzed in search of optimal conditions of carbon dioxide conversion. In these papers, it is shown that the plasma technologies are very promising for conversion of $\mathrm{CO}_{2}$, but the creation of efficient industrial technologies is impossible without additional fundamental research to better understand the basic mechanisms of complex plasma-chemical processes occurring in discharges in $\mathrm{CO}_{2}$.

The main attention in the mentioned researches was paid to discharges at atmospheric and medium pressure, and rarely to low-pressure discharges. In the paper [11] the results of experimental study of efficiency of carbon dioxide conversion to $\mathrm{CO}$ and $\mathrm{O}_{2}$ in inductively coupled plasma in the RF power range $5 \ldots .500 \mathrm{~W}$ at low gas pressure of $1 \ldots 100 \mathrm{mT}$ Torr was presented. Using the mass spectrometry method the dependencies of the conversion rate and the energy efficiency of carbon dioxide conversion on the gas pressure and the power deposited in the discharge was measured. The maximum achieved conversion rate was shown as $82 \%$, while the energy conversion efficiency was up to $50 \%$. It is important that according to the mentioned research the maximum conversion rate is achieved at the lowest pressures (down to $1 \mathrm{mTorr}$ ) and at the highest pressures of the researched range (up to $100 \mathrm{mTorr}$ ) while at intermediate pressures the conversion rate has a minimum. Thus, the low-pressure region can be advantageous in some specific cases, but the question of the most effective type of discharge for the $\mathrm{CO}_{2}$ conversion at low pressures is still open. The main aim of the present research is the comparative study of the carbon dioxide splitting to $\mathrm{CO}$ and $\mathrm{O}_{2}$ in plasmas at low gas pressure, namely, inductively coupled plasma, magnetized plasma of magnetron discharge, and Hall-type ion source with highly energetic electrons.

\section{EXPERIMENTAL TECHNIQUES}

Plasma sources and experimental setups used in the present study were described elsewhere [11 - 13]. Two vacuum installations were used named here as Setup 1 and Setup 2.

In the Setup 1 a planar magnetron (Magnetron 1) with permanent magnets was used (Fig. 1). The magnetron power supply allows to bias the magnetron target at up to $1 \mathrm{kV}$ negative potential at the discharge current up to $20 \mathrm{~A}$, maximum power of the supply is $6 \mathrm{~kW}$. The magnetron target of $170 \mathrm{~mm}$ diameter was made of stainless steel.

The ICP plasma source was placed inside the vacuum chamber of the Setup 1. Plasma in such source is concentrated in the discharge chamber made of a ceramic tube (see Fig. 1).

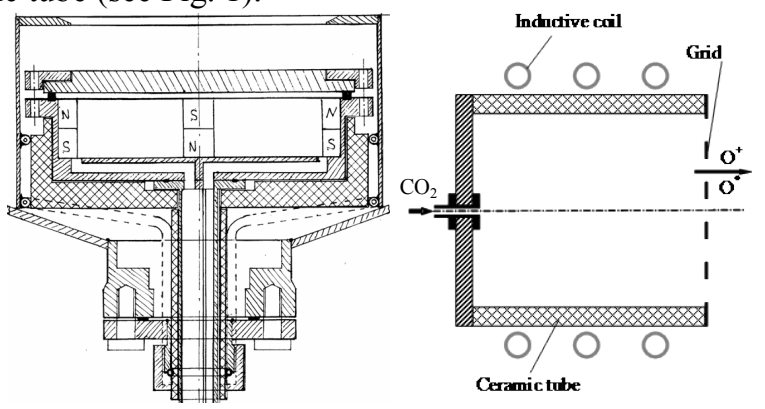

Fig. 1. Internal structure of Magnetron 1 (left) and ICP source (right)

At the source exit the perforated metal screen is placed which restricts the plasma and provides a pressure drop between the source volume and the technological chamber. The RF inductive plasma source is supplied with the RF power up to $1 \mathrm{~kW}$ at the frequency of $13.56 \mathrm{MHz}$. Fig. 2 shows photo of the ICP source and magnetron discharge in simultaneous operation in Setup 1.

The Setup 2 was equipped with the combined magnetron-ion-source sputtering system (MISSS) described in detail in [13]. The schematic diagram of the MISSS 
device with diagnostic equipment is presented in Fig. 3. The device contains magnetic system, which is common for the magnetron discharge and the Hall-type ion source. The steel case being a part of the magnetic system serves also as a cathode of the ion source and an anode for magnetron discharge.

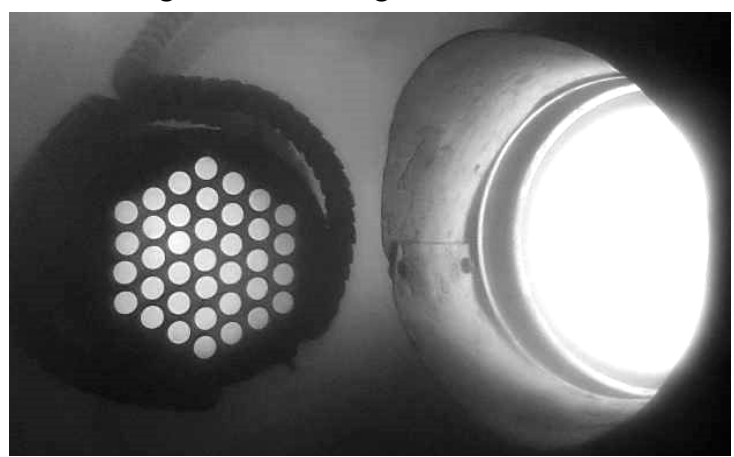

Fig. 2. Photo of the ICP source and magnetron discharge in simultaneous operation in Setup 1

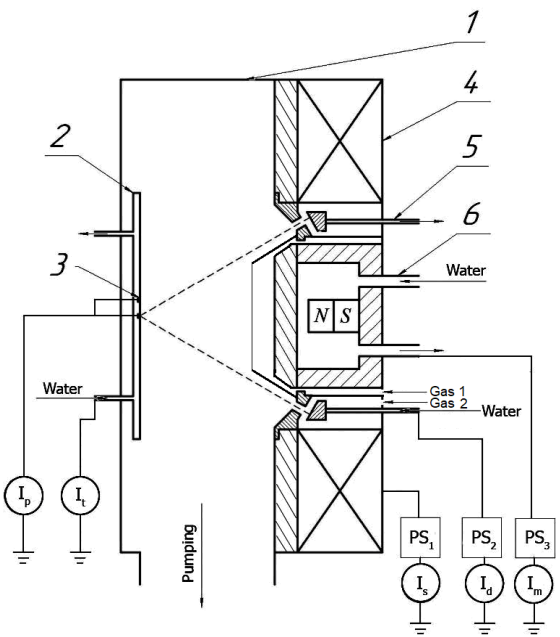

Fig. 3. Schematic diagram of the MISSS setup:

1 -vacuum chamber; 2 - water cooled sample holder;

3 -flat probe for ion current density measurement;

4 -solenoid; 5 -anode of the ion source; 6 -Magnetron 2

The ion source forms a conical coinciding beam of gas ions with the angle of $60^{\circ}$, diameter of $100 \mathrm{~mm}$ (near the anode 5) and thickness of about $5 \mathrm{~mm}$. The flat conductive electrode 2 with diameter of $140 \mathrm{~mm}$ located at a distance of $100 \mathrm{~mm}$ from the end of the ion source is used for sample holding and ion beam monitoring.

The planar magnetron (Magnetron 2) with a stainless steel target (76 $\mathrm{mm}$ in diameter and $6 \mathrm{~mm}$ in thickness) was mounted inside the conical ion beam. DC power up to $300 \mathrm{~W}$ was applied to the magnetron. The conical magnetron anode forms a subchamber where the magnetron plasma is localized. The gas feeding can be forwarded either through the conical cavity of the magnetron subchamber or through the anode cavity of the ion source. In the both cases the total gas flow passes through the active plasma region before entering the vacuum chamber and then the pumping system.

Both devices of the MISSS may be operated simultaneously, however, in the present study they operated separately with the $\mathrm{CO}_{2}$ feeding to the corresponding channel. Fig. 4 shows view of MISSS operation in the both regimes.
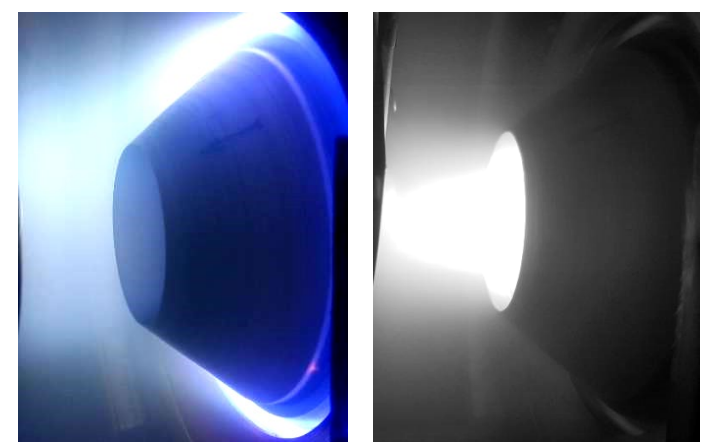

Fig. 4. Photo of MISSS in Setup 1 with the ion source (left) and the Magnetron 2 (right) in operation

In the Setup 1 the $1 \mathrm{~m}$ long vacuum chamber of $0.7 \mathrm{~m}$ diameter was pumped by a turbomolecular pump with 2500 1/s rate while in the Setup 2 the vacuum chamber with dimensions $240 \times 240 \times 120 \mathrm{~mm}$ was pumped by a turbomolecular pump TMN-1500, with pumping rate of $700 \mathrm{l} / \mathrm{s}$. The experiments were conducted within the pressure range $0.5 \ldots 3 \mathrm{mT}$ Torr which corresponds to different gas flow rates for the Setup 1 and the Setup 2 due to different pumping throughput. Fig. 5 shows the pressure dependence on the $\mathrm{CO}_{2}$ mass flow rate for the two setups.

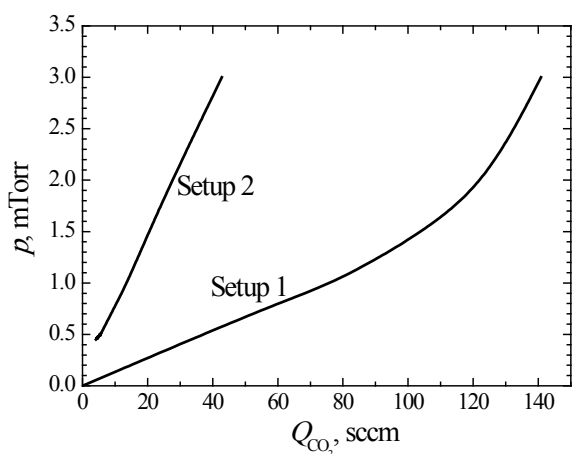

Fig. 5. Pressure dependence in the vacuum chambers on $\mathrm{CO}_{2}$ mass flow
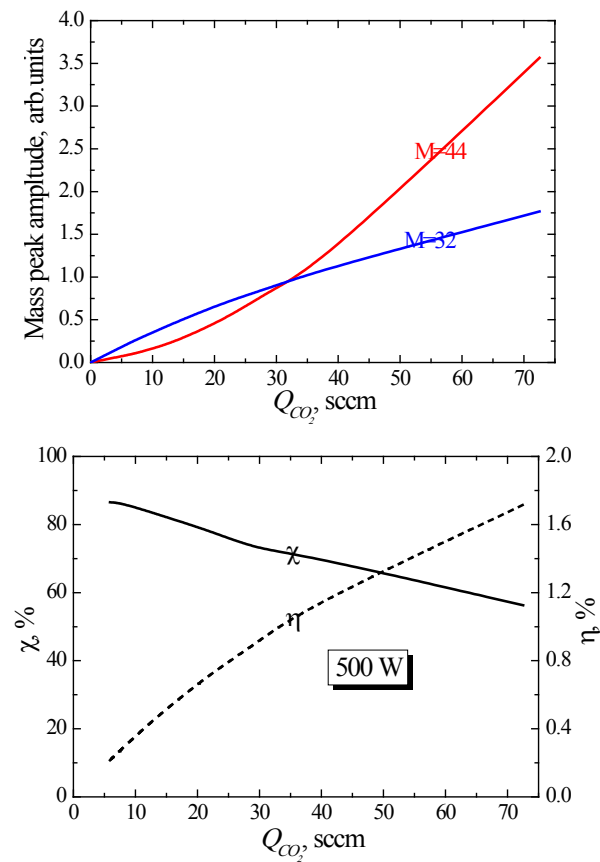

Fig. 6. Carbon dioxide conversion in ICP source in dependence on the gas flow

Method for mass-spectrometric evaluation of carbon dioxide conversion was described in the paper [14]. The conversion rate $\chi$ is determined using the amplitudes of 
mass peaks of $\mathrm{CO}_{2}\left(M_{44}\right)$ and $\mathrm{O}_{2}\left(M_{32}\right)$. In addition in the present research we used the following expression for the conversion rate allowing compensation of massspectrometer pumping instability:

$$
\chi=\frac{k_{32} M_{32}}{\left(k_{32} M_{32}+M_{44}\right)}, \text { where } k_{32}=2 \cdot 1.3 .
$$

Following the paper [15], let us define the Specific energy input $(S E I)$ as

$S E I\left[\mathrm{~J} / \mathrm{cm}^{3}\right]=60[\mathrm{~s} / \mathrm{min}] \cdot P_{R F}[\mathrm{~W}] / Q_{C O 2}[\mathrm{sccm}]$, where $\mathrm{Q}_{\mathrm{CO} 2}$ is $\mathrm{CO}_{2}$ flow rate in standard cubic centimeters per minute [sccm].

Next, the energy efficiency of the conversion $\eta$ is defined as

$$
\eta=\frac{\chi \cdot \Delta H}{S E I}, \text { where } \Delta H=283 \mathrm{~kJ} / \mathrm{mol}=11.55 \mathrm{~J} / \mathrm{cm}^{3} .
$$

\section{EXPERIMENTAL RESULTS}

Fig. 6 illustrates the carbon dioxide conversion in ICP source in dependence on the gas flow at the constant RF power of $500 \mathrm{~W}$. The upper plot shows the mass peaks amplitudes in dependence on the gas flow. It is clearly visible that the Oxygen peak exceeds the $\mathrm{CO}_{2}$ peak at the lowest flow rates that means the conversion rate is high while the flow rate increase causes the decrease of the conversion rate that is seen from the bottom plot in exact quantities. At the lowest gas flow rate the conversion is maximal reaching as high value as $85 \%$. In contrast, the energy efficiency of the conversion grows monotonically with the gas flow being always less then $2 \%$.
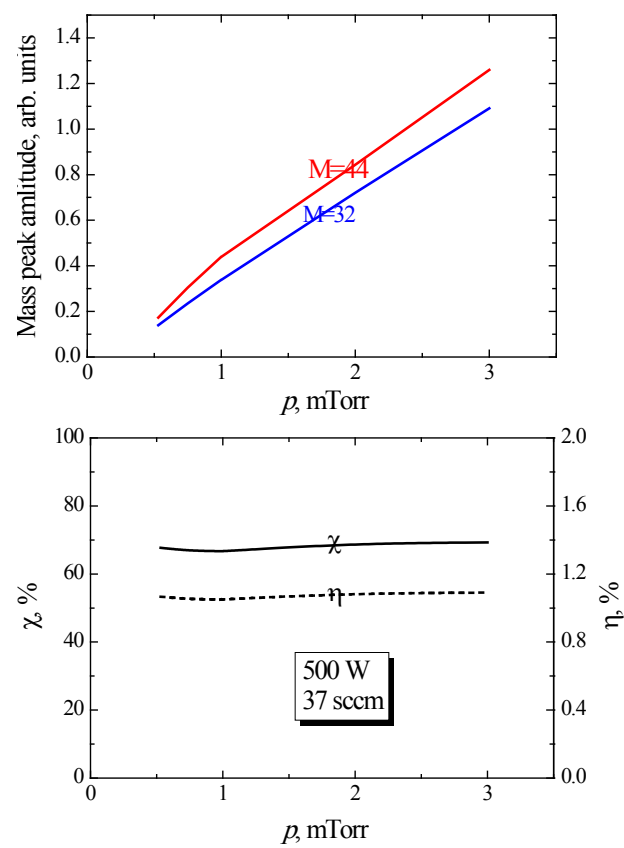

Fig. 7. Carbon dioxide conversion in ICP source in dependence on the gas pressure with constant gas flow

Fig. 7 shows the same results but with the constant $\mathrm{CO}_{2}$ flow rate and RF power input to the ICP source. The gas pressure was changed in the vacuum chamber varying the pumping rate by the valve regulation. In this case both the conversion rate and the energy efficiency of the conversion are almost independent on the pressure. It should be noted that the dependences shown in the Fig. 7 may be redrawn versus the pressure using the dependence shown in Fig. 5. But these two pressure dependences are completely different that confirms the dramatic role of the flow rate for the process of plasma conversion of carbon dioxide.

The $\mathrm{CO}_{2}$ conversion dependence on $\mathrm{RF}$ power input to the inductively coupled plasma is shown in Fig. 8 . With the RF power increase, the Oxygen part in the exhaust gas mixture changes from zero value to the major part. The conversion $\chi$ growth from zero to $75 \%$ while the energy efficiency of the conversion decreases continuously from approximately $2 \%$ at $150 \mathrm{~W}$ to about $1.2 \%$ at $700 \mathrm{~W}$.
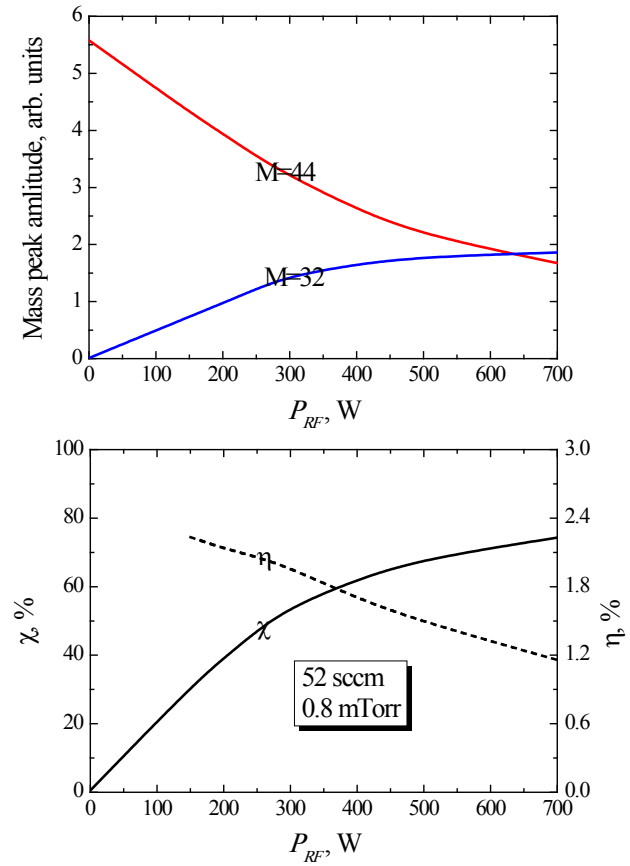

Fig. 8. Carbon dioxide conversion in ICP source in dependence on $R F$ power

Now, let us consider the same dependencies for the carbon dioxide conversion in magnetron discharge. The dependencies for Magnetron 1 are shown in Figs. 9-11. One can see from the figures that the conversion is not so effective as in ICP case. The conversion rate $\chi$ is less then $50 \%$ at any parameters that can be explained by the fact that the gas was fed into the vacuum chamber not exactly at the magnetron plasma region so there is a way for some molecules to go to the pump without interaction with the magnetron plasma. The energy efficiency $\eta$ is also quite low that is natural for rather high power input to the discharge. In contrast to the ICP case the conversion efficiency is growing with the pressure at the constant $\mathrm{CO}_{2}$ flow rate.

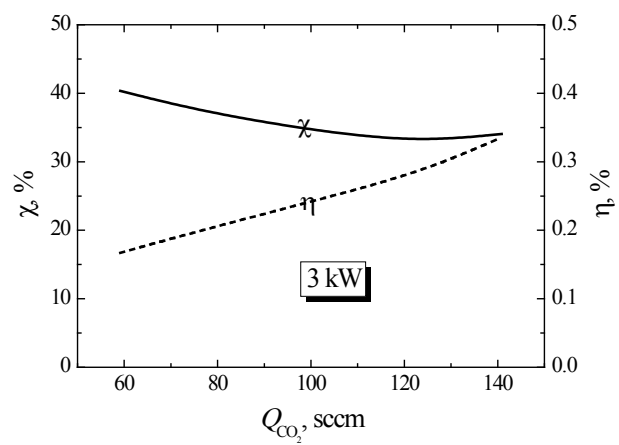

Fig. 9. Carbon dioxide conversion in Magnetron 1 plasma in dependence on the gas flow 


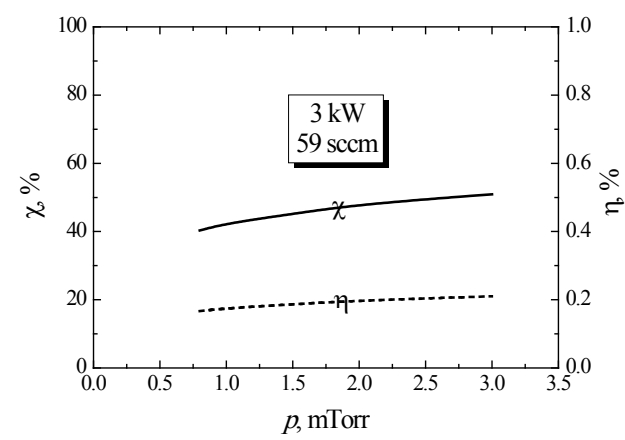

Fig. 10. Carbon dioxide conversion in Magnetron 1 plasma in dependence on the gas pressure with constant

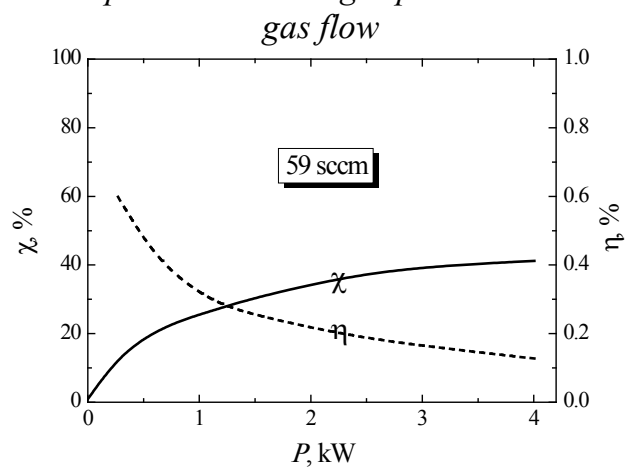

Fig. 11. Carbon dioxide conversion in Magnetron 1 plasma in dependence on RF power

Let us review now $\mathrm{CO}_{2}$ conversion results in plasma of the Hall-type ion source. One can expect significant difference comparing to the ICP and the magnetron cases. It is known that the electron energies in the anode layer of the discharge in crossed electric and magnetic fields may reach the values of hundreds of electron-volts. From the other side, the axial extent of the anode layer containing the high-energy electrons is only few millimeters that reduces the electron-molecule interaction probability on the molecule way through the discharge gap.

It should be noted initially that the ion source can operate in two regimes depending on the gas pressure. Current-voltage characteristics of the ion source at three different gas pressures are presented in Fig. 12. At low pressure (see curve for $0.8 \mathrm{mTorr}$ ) the discharge exists in high-voltage acceleration mode, but when the gas pressure in the discharge gap overcomes some critical value, the discharge jumps from acceleration to plasma regime ( 2 mTorr curve). Not only the current-voltage characteristics are essentially different in these regimes, the plasma distribution outside the source is also changed. In contrast to the acceleration regime, in the low-voltage regime the space outside the source is filled by plasma. Despite the plasma possess low electron temperature the pathway of the gas molecules trough the plasma is much longer. As a result the conversion rate is higher just in the low-voltage regime of the ion source. Generally, all the obtained results for the conversion rate are below $25 \%$ while the energy efficiency of the conversion is less then $1 \%$ (Fig. 13).

The following series of experimental results is devoted to carbon dioxide conversion in plasma of Magnetron 2. Figs. 14, 15 show the dependence on power and $\mathrm{CO}_{2}$ flow rate, respectively. The conversion rate is similar to the case of Magnetron 1, while the energy efficiency of the conversion is much better.

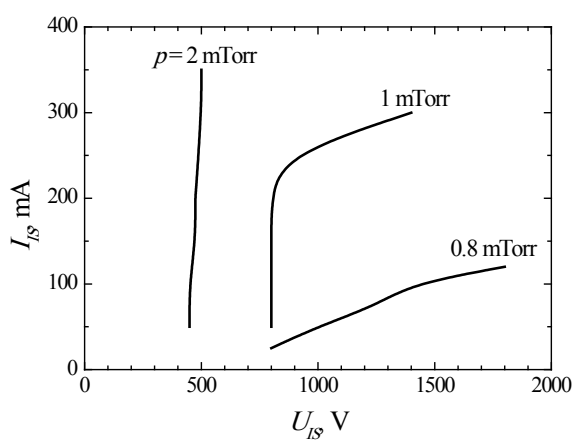

Fig. 12. Current-voltage characteristics of the ion source at three different gas pressures

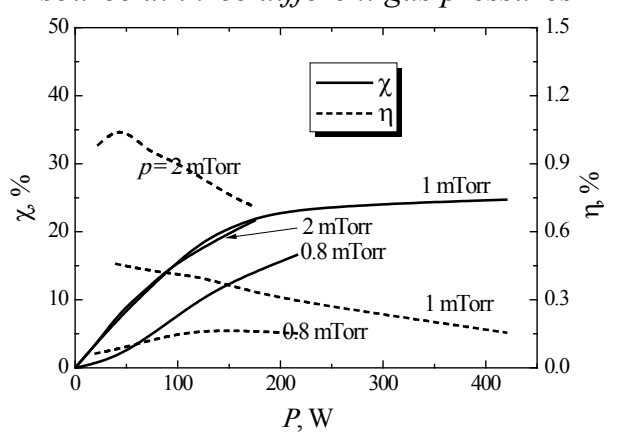

Fig. 13. Carbon dioxide conversion in the ion source plasma in dependence on input power

It should be noted that the working area diameter of the Magnetron 1 target is about $140 \mathrm{~mm}$ while for the Magnetron 2 this value is about $50 \mathrm{~mm}$. Thus, the area ratio of these two magnetrons is about one order of magnitude. The power ratio $(3 \mathrm{~kW}$ vs. $300 \mathrm{~W})$ is of the same order that means the power density is similar for the both devices. The main difference between the magnetrons from the point of view of $\mathrm{CO}_{2}$ conversion is that the gas feeding is performed through the cavity surrounding the Magnetron 2. The cavity is completely filled with the dense magnetron plasma that ensures effective $\mathrm{CO}_{2}$ interaction with plasma.

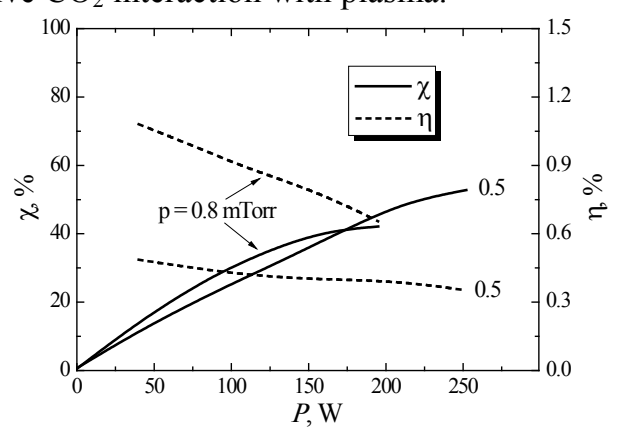

Fig. 14. Carbon dioxide conversion in the Magnetron 2

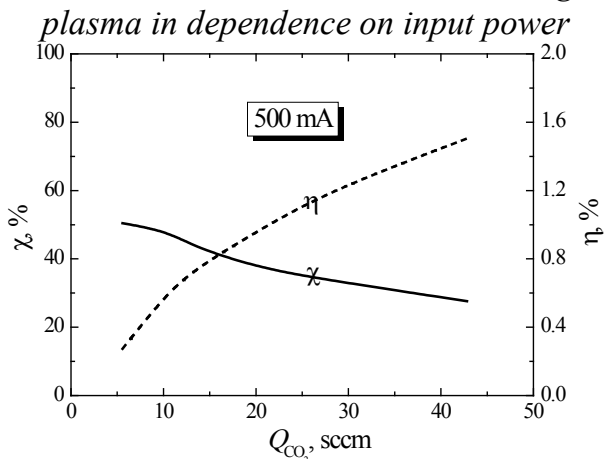

Fig. 15. Carbon dioxide conversion in the Magnetron 2 plasma in dependence on the gas flow 

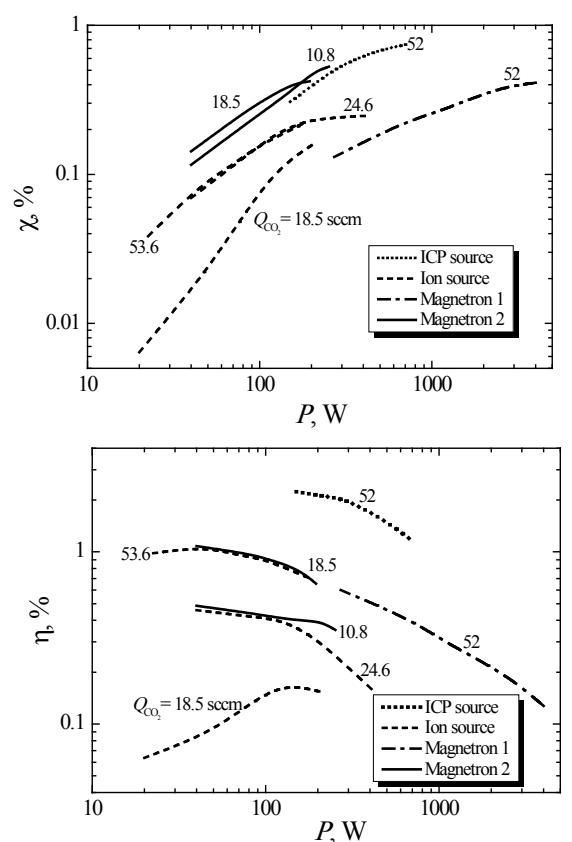

Fig. 16. Comparison of carbon dioxide conversion efficiency in all the researched devices in dependence on input power

Finally, let us gather all the available data in generalized plots in order to compare performance of all the tested devices. Fig. 16 presents the conversion efficiency in dependence on the input power. It is clear that the most efficient conversion is observed in the ICP source. The magnetron discharges are less efficient, next is the ion source in plasma regime, and the worst results are for the ion source in acceleration regime.

Further detalization gives Fig. 17 where dependencies on the gas flow are presented for the both magnetrons and the ICP source. The maximum conversion is reached for the ICP source, while from the point of view of the energy efficiency of the conversion the Magnetron 2 is advantageous due to lower consumed power.
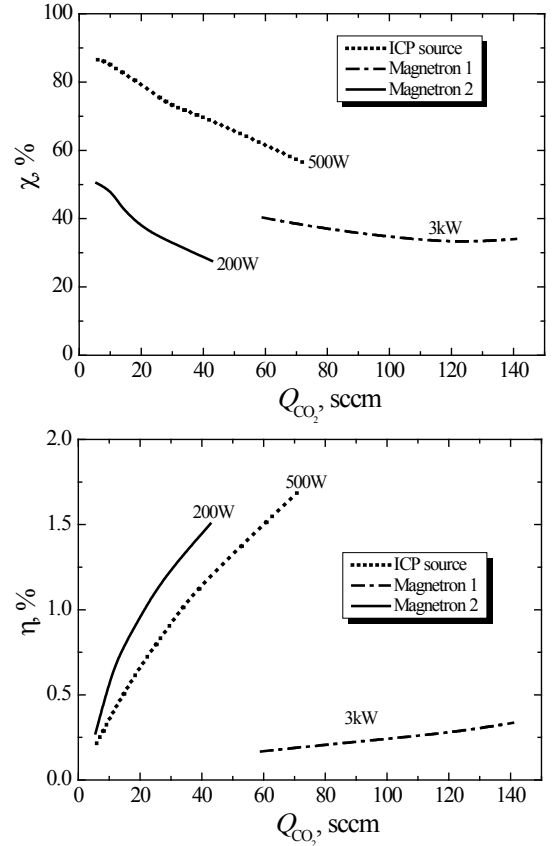

Fig. 17. Comparison of carbon dioxide conversion rate in all the researched devices in dependence on the gas flow
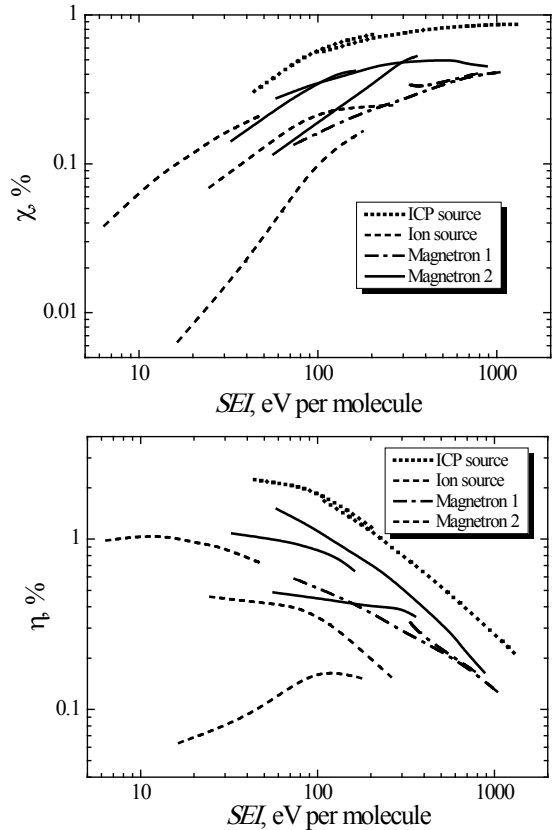

Fig. 18. Comparison of carbon dioxide conversion efficiency in all the researched devices in dependence on the specific energy input

The plots in Fig. 18 contain curves for different gas flows that complicates the comparison. In order to present the results in dependence on universal parameter taking into account both the input power and the gas flow rate the curves were replotted verus the specific energy input SEI that is shown in Fig. 18. It can be seen that all the curves excluding the dependencies for the ion source in acceleration mode are placed within a band, which has a "knee" near SEI of $100 \mathrm{eV}$ per molecule. Lower values are insufficient for high conversion rate while at higher values the energy efficiency of the conversion drops quickly.

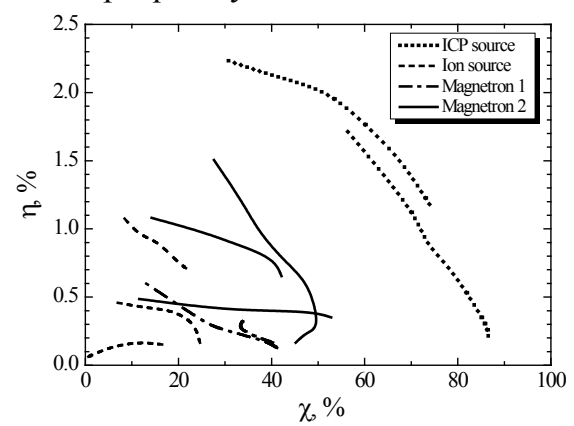

Fig. 19. $\eta-\chi$ plots for all the researched devices

\section{CONCLUSIONS}

The final picture (Fig. 19) generalizes all the obtained data in $\eta-\chi$ coordinates. It can be concluded from the figure that high $\eta$ and $\chi$ values are unreachable simultaneously and for practical applications the optimal operation regime should be chosen in dependence of primary task, focusing either on the conversion rate or on the energy efficiency. The best combination of high conversion rate with significant energy efficiency of the conversion is demonstrated by the ICP source. This looks natural since the RF ICP is an electrodeless discharge where the most valuable part of the input energy goes into the plasma creation and chemical reactions 
while in the high-voltage discharges significant energy is spent for ion acceleration. The dependence of the conversion efficiency on the electron temperature noted in [14] allowed to hope for the high conversion in the Hall-type ion source in acceleration regime with highenergy electrons present. However, despite high electron energies, the discharge zone in this case is very short, and low voltage plasma regime is advantageous due to higher plasma densities and wider geometrical plasma extent.

\section{REFERENCES}

1. D. Wu, R.A. Outlaw, and R.L. Ash. Extraction of oxygen from $\mathrm{CO}_{2}$ using glow-discharge and permeation techniques // J. Vac. Sci. Technol. A. 1996, v. 14, № 2, p. 408-414.

2. L.M. Zhou, B. Xue, U. Kogelschatz, and B. Eliasson. Nonequilibrium Plasma Reforming of Greenhouse Gases to Synthesis Gas // Energy and Fuels. 1998, v. 12, p. 1191-1199.

3. B. Hu, C. Guild, S.L. Suib. Thermal, electrochemical, and photochemical conversion of $\mathrm{CO}_{2}$ to fuels and value-added products // Journal of $\mathrm{CO}_{2}$ Utilization. 2013, v. 1, p. 18-27.

4. Ch. Berenguer and K. Katsonis. Global Modeling of $\mathrm{CO}_{2}$ Discharges with Aerospace Applications // $\mathrm{Ad}$ vances in Aerospace Engineering. 2014, Article ID 847097, $17 \mathrm{p}$.

5. T. Kozak and A. Bogaerts. Splitting of $\mathrm{CO}_{2}$ by vibrational excitation in non-equilibrium plasmas: a reaction kinetics model // Plasma Sources Sci. Technol. 2014, v. 23, № 4, p. 045004.

6. Ch. De Bie, J. van Dijk, A. Bogaerts. The Dominant Pathways for the Conversion of Methane into Oxygenates and Syngas... // J. Phys. Chem. C. 2015, v. 119 , p. 22331-22350.
7. A. Bogaerts, T. Kozak, K. van Laer and R. Snoeckx. Plasma-based conversion of $\mathrm{CO}_{2}$ : current status and future challenges // Faraday Discuss. 2015, v. 183, p. 217-232.

8. G.J. van Rooij et al. Taming microwave plasma to beat thermodynamics in $\mathrm{CO}_{2}$ dissociation // Faraday Discuss. 2015, 16 p. (DOI: 10.1039/c5fd00045a).

9. R. Aerts, W. Somers, and A. Bogaerts. Carbon Dioxide Splitting in a Dielectric Barrier Discharge Plasma // ChemSusChem. 2015, v. 8, p. 702-716.

10. R. Snoeckx, S. Heijkers, K. Van Wesenbeeck, $\mathrm{S}$. Lenaerts and A. Bogaerts. $\mathrm{CO}_{2}$ conversion in a dielectric barrier discharge plasma // Energy Environ. Sci. 2016, v. 9, p. 999-1011.

11. S. Yakovin, A. Zykov, S. Dudin, A. Dakhov, N. Yefymenko. Investigation of interaction between ion-beam plasma and processed surface during the synthesis of tantalum diboride and pentaoxide // Problems of Atomic Science and Technology. Series “Plasma Physics”. 2019, № 1, p. 229-232.

12. S. Yakovin, S. Dudin, A. Zykov, V. Farenik. Integral cluster set-up for complex compound composites syntesis // Problems of Atomic Science and Technology. Series “Plasma Physics”. 2011, № 1, p. 152-154.

13. S. Dudin, O. Tkachenko, A. Shchybria, S. Yakovin, A. Zykov, N. Yefymenko. Design and research of combined magnetron-ion-beam sputtering system // Problems of Atomic Science and Technology. Series "Plasma Physics". 2018, № 6, p. 263-266.

14. S.V. Dudin, A.N. Dakhov. Conversion of carbon dioxide in low-pressure plasma // Problems of Atomic Science and Technology. Series "Plasma Physics”. 2018, № 6, p. 194-197.

15. R. Snoeckx and A. Bogaerts. Plasma technology - a novel solution for $\mathrm{CO}_{2}$ conversion? // Chem. Soc. Rev. 2017, v. 46, p. 5805-5863.

Article received 10.06.2019

\section{ПЛАЗМЕННАЯ КОНВЕРСИЯ УГЛЕКИСЛОГО ГАЗА В ГАЗОВЫХ РАЗРЯДАХ НИЗКОГО ДАВЛЕНИЯ}

\section{С.В. Дудин, А.В. Зыков, С.Д. Яковин}

Представлены экспериментальные результаты сравнительного исследования эффективности конверсии диоксида углерода в $\mathrm{CO}$ и $\mathrm{O}_{2}$ в плазме разрядов низкого давления. Индуктивно связанный источник плазмы, магнетронный разряд и разряд с анодным слоем в ионном источнике холловского типа использовались в диапазоне давлений $\mathrm{CO}_{2}$ от 0,5 до 3 мТорр. Показано, что наилучшее сочетание высокого коэффициента конверсии со значительной энергоэффективностью демонстрирует источник плазмы с ВЧ-разрядом индукционного типа.

\section{ПЛАЗМОВА КОНВЕРСІЯ ВУГЛЕКИСЛОГО ГАЗУ В ГАЗОВИХ РОЗРЯДАХ НИЗЬКОГО ТИСКУ \\ С.В. Дудін, О.В. Зиков, С.Д. Яковін}

Представлено експериментальні результати порівняльного дослідження ефективності конверсії діоксиду вуглецю в $\mathrm{CO}$ i $_{2}$ у плазмі розрядів низького тиску. Джерело індуктивно зв'язаної плазми, магнетронний розряд і розряд з анодним шаром в іонному джерелі холлівського типу використовувалися в діапазоні тисків $\mathrm{CO}_{2}$ від 0,5 до 3 мТорр. Показано, що оптимальне поєднання високого коефіцієнта конверсії зі значною енергоефективністю демонструє джерело плазми з ВЧ-розрядом індукційного типу. 